\title{
Goniossinéquia como complicação na esclerectomia profunda não penetrante por uso inadvertido de midriático: relato de caso
}

\author{
Goniosynechiae as a complication of non-penetrating deep sclerectomy \\ by inappropriate use of mydriatic: case report
}

\author{
Rinalva Tenório Vaz ${ }^{1}$ \\ Patricia Capua Vieira da Silva ${ }^{2}$ \\ Giovanni Nicola Umberto Italiano Colombini ${ }^{3}$
}

Trabalho realizado no Departamento de Glaucoma do Instituto Benjamin Constant - Rio de Janeiro (RJ) - Brasil.

${ }^{1}$ Estagiária do Departamento de Glaucoma do Instituto Benjamin Constant - Rio de Janeiro (RJ) - Brasil.

${ }^{2}$ Residente do Instituto Benjamin Constant - Rio de Janeiro (RJ) - Brasil.

${ }^{3}$ Professor Responsável pela Disciplina de Oftalmologia da Escola de Medicina e Cirurgia do Rio de Janeiro - UNIRIO; Responsável pelo Departamento de Glaucoma do Instituto Benjamin Constant - Rio de Janeiro (RJ) - Brasil.

Endereço para correspondência: Rinalva Tenório Vaz. Rua Clovis Beviláqua, 163/802 - Recife (PE)

CEP 50710-330

E-mail: rtvaz2@hotmail.com

Recebido para publicação em 19.10.2007

Última versão recebida em 24.11.2007

Aprovação em 13.12.2007

\begin{tabular}{|l|}
\hline RESUMO \\
\hline A esclerectomia profunda não penetrante tem sido uma alternativa à tra- \\
beculectomia, pois tem como vantagem a redução da pressão intra-ocular \\
(PIO), sem penetrar na câmara anterior. Desta forma, evitando descom- \\
pressão brusca, câmara anterior rasa. Neste trabalho, descrevemos o caso \\
de uma paciente, 53 anos, negra, com diagnóstico de glaucoma primário de \\
ângulo aberto, com controle clínico insatisfatório e que foi submetida à \\
esclerectomia profunda não penetrante. A paciente evoluiu com formação \\
de goniossinéquia na região da esclerectomia, após uso inadvertido de \\
colírio midriático no pós-operatório, levando ao aumento da PIO e conse- \\
qüente falência da cirurgia. O uso de colírio midriático no pós-operatório \\
da esclerectomia profunda não está indicado, pois neste caso, ocasionou \\
o insucesso da cirurgia.
\end{tabular}

Descritores: Glaucoma de ângulo aberto/cirurgia; Esclera/cirurgia; Esclerostomia/métodos, complicações pós-operatórias; Soluções oftálmicas/efeitos adversos; Relatos de casos [Tipo de publicação]

\section{INTRODUÇÃO}

A esclerectomia profunda não penetrante (EPNP) tem sido uma alternativa à trabeculectomia, pois tem como principal vantagem a redução da pressão intraocular (PIO) sem penetrar a câmara anterior $(\mathrm{CA})^{(1-2)}$. A maior resistência do humor aquoso (HA) encontra-se no trabeculado justacanalicular e parede interna do canal de Schlemm. O sucesso deste procedimento está em remover fisicamente estas estruturas que provocam resistência ao escoamento do humor aquoso, sem comprometer a integridade estrutural do olho. Desta forma evita-se a descompressão brusca, CA rasa e formação de catarata ${ }^{(1)}$. A indicação formal da cirurgia não penetrante é sempre o glaucoma primário de ângulo aberto.

O objetivo deste trabalho é descrever uma complicação pós-operatória na esclerectomia profunda não penetrante, por uso inadvertido de colírio midriático.

\section{RELATO DE CASO}

M. J. C., 53 anos, sexo feminino, negra, natural e procedente do Rio de Janeiro. Antecedentes pessoais e familiares irrelevantes para o caso.

A paciente procurou o ambulatório geral do Instituto Benjamin Constant em 2004, com diagnóstico de glaucoma, e em tratamento com maleato de timolol 
0,5\%. Referia baixa visual progressiva em ambos os olhos por progressão da doença, já com cegueira no olho direito.

No exame oftalmológico observou-se acuidade visual de SPL (sem percepção luminosa) no olho direito e 20/160 no olho esquerdo com a melhor correção. À biomicroscopia apresentou córnea transparente, câmara anterior ampla, íris e cristalino sem alterações. O exame de fundo de olho mostrou atrofia óptica glaucomatosa no olho direito e disco óptico glaucomatoso, com escavação $0,9 / 0,9$ no olho esquerdo. A gonioscopia realizada com lente de três espelhos de Goldmann revelou ângulo aberto em $360^{\circ} \mathrm{com}$ seio camerular livre. A campimetria computadorizada central do olho esquerdo mostrou lesão tubular. MD: 26,6 dB. A paciente fazia uso de colírios hipotensores: associação fixa de maleato de timolol $0,5 \%$ com tartarato de brimonidina $0,2 \%$ e travoprosta. PIO: $24 \mathrm{mmHg}$ às $10 \mathrm{~h}$ medida com tonômetro de aplanação de Goldmann.

Foi indicado tratamento cirúrgico para controle pressórico no olho esquerdo. Em novembro de 2006, a paciente foi submetida à esclerectomia profunda não penetrante (sem implante de colágeno) com aplicação de mitomicina. A cirurgia transcorreu sem intercorrências. No primeiro dia de pós-operatório, com PIO de $8 \mathrm{mmHg}$, a paciente fez uso inadvertido de colírio midriático (tropicamida 1\%), o que levou à formação de goniossinéquia no local da esclerectomia (Figura 1), com conseqüente aumento da PIO e falência da cirurgia. A PIO medida pela manhã no $8^{\circ}, 15^{\circ}$ e $30^{\circ}$ dia de pós-operatório foi consecutivamente: 30,32 e $30 \mathrm{mmHg}$.

\section{DISCUSSÃO}

Trabalhos recentes têm demonstrado a eficácia da esclerectomia profunda como procedimento simples para controle do glaucoma primário de ângulo aberto ou combinado a extração de catara$\mathrm{ta}^{(3-4)}$. Estes estudos mostram que a redução da PIO por meio da EPNP é comparável aos resultados obtidos com trabeculectomia, em pacientes acompanhados por 12 meses após a cirurgia ${ }^{(4)}$.

Esta nova técnica de cirurgia filtrante consiste em aumentar seletivamente o fluxo de drenagem do aquoso através do trabeculado justacanalicular e canal de Schlemm sem penetrar

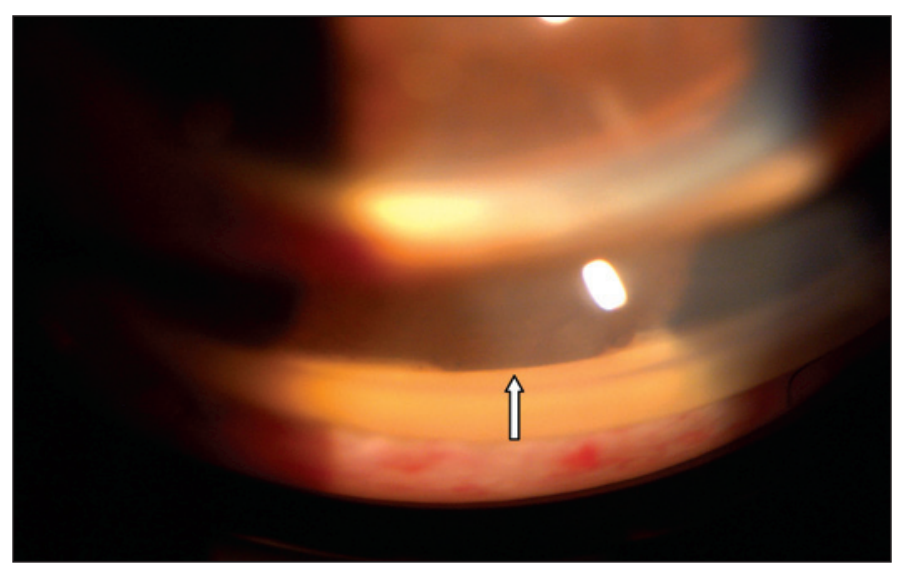

Figura 1 - Goniossinéquia trapezoidal em local correspondente à região da esclerectomia profunda não penetrante (seta branca) na câmara anterior ${ }^{(1)}$. O sucesso do procedimento filtrante depende dos seguintes fatores essenciais: profundo conhecimento da anatomia ocular, cuidadosa e precisa técnica de dissecção e instrumentos cirúrgicos de alta precisão ${ }^{(2)}$.

Além das vantagens anteriormente citadas da EPNP, como: preservar a integridade estrutural do olho e evitar descompressão brusca, autores sugerem que a perda de células endoteliais após EPNP é menor que aquela encontrada na trabeculectomia ${ }^{(5)}$.

As principais complicações da EPNP são: ruptura da membrana trabeculado-Descemet, hipertensão ocular pós-operatória, fibrose da bolha filtrante, bolha policística, não identificação do canal de Schlemm e encarceramento da íris ${ }^{(6-7)}$. Grandes rupturas da membrana trabeculado-Descemet são convertidas em procedimento penetrante (trabeculectomia). Outras complicações clássicas de cirurgia filtrante também podem ocorrer, no entanto, com menor prevalência, tais como o descolamento de coróide, hipotonia prolongada, hifema, câmara anterior rasa e o teste de Seidel positivo ${ }^{(5)}$.

\section{ABSTRACT}

Non-penetrating deep sclerectomy has been an alternative to trabeculectomy, because it has the advantage of reducing intraocular pressure (IOP), without penetrating the anterior chamber. Thus, it avoids a sudden decompression and a plain anterior chamber. In this paper, we described a case of a female patient, 53 years old, black, with diagnosis of open-angle primary glaucoma, with unsatisfactory clinical control and who was submitted to non-penetrating deep sclerectomy. The patient developed goniosynechiae at the site of the sclerectomy, after inappropriate use of mydriatic eye-drops during the postoperative period, leading to an increase of IOP and, therefore, failure of the surgery. The use of mydriatic eye-drops during the postoperative period of deep sclerectomy is not indicated, because in this case, it led to surgery failure.

Keywords: Glaucoma, open-angle/surgery; Sclera/surgery; Sclerostomy/methods, postoperative complications; Ophthalmic solutions/adverse effects; Case reports [Publication type]

\section{REFERÊNCIAS}

1. Roy S, Mermoud A.[How does nonpenetrating surgery work?]. J Fr Ophtalmol. 2006;29(10):1167-74. French.

2. Roy S, Mermoud A. [Deep nonpenetrating sclerectomy: technical aspects]. J Fr Ophtalmol. 2006;29(10):1160-6. French.

3. Lüke C, Dietlein TS, Lüke M, Konen W, Krieglstein GK. Phaco-trabeculotomy combined with deep sclerectomy, a new technique in combined cataract and glaucoma surgery: complication profile. Acta Ophthalmol Scand. 2007;85(2):143-8.

4. Marek R, Joanna W, Lewczuk K, Siemiatkowska A, Stankiewicz A. Efficacy and safety of deep sclerectomy and phacoemulsification and deep sclerectomy in clinical of Military Health Service Institute-yearly observations. Klin Oczna. 2006;108(10-12):385-91.

5. Arnavielle S, Lafontaine PO, Bidot S, Creuzot-Garcher C, D'Athis P, Bron AM. Corneal endothelial cell changes after trabeculectomy and deep sclerectomy. J Glaucoma. 2007;16(3):324-8.

6. Roy S, Mermoud A. [Complications of deep nonpenetrating sclerectomy]. J Fr Ophtalmol. 2006;29(10):1180-97. French.

7. Hamard P. Management of non penetrating surgery failure. J Fr Ophtalmol. 2003;26(Spec № 2):S18-22. 